\title{
Recyclable Cyclohexanediamine Derivatives as Organocatalysts: Organocatalytic Reduction with Trichlorosilane and Aldol Reaction
}

\author{
Yuya Tanimura, Kaori Ishimaru* \\ Department of Chemistry, National Defense Academy, Yokosuka, Japan \\ Email: *kaoriisi@nda.ac.jp
}

Received October 24, 2013; revised November 26, 2013; accepted December 2, 2013

Copyright (C) 2013 Yuya Tanimura, Kaori Ishimaru. This is an open access article distributed under the Creative Commons Attribution License, which permits unrestricted use, distribution, and reproduction in any medium, provided the original work is properly cited.

\begin{abstract}
Reduction of ketimine with trichlorosilane was carried out using bisformamide catalyst 1a derived from cyclohexanediamine to give the corresponding product in $81 \%$ yield with $39 \%$ ee. Deprotection of the formyl groups of the catalysts 1 gave the corresponding diamines 2 which were utilized in aldol reaction of acetone with 4-nitrobenzaldehyde. The reaction using $\mathbf{2 b}$ in brine afforded the aldol adduct in $81 \%$ yield with $29 \%$ ee.
\end{abstract}

Keywords: Aldol Reaction; Cyclohexanediamine; Organocatalysis; Recyclable; Reduction

\section{Introduction}

The field of organocatalysis has been rapidly growing in recent years because the reactions have evolved into a non-metal, abundant, and environmentally benign methodology [1-3]. Recently, we have succeeded in asymmetric allylation reaction of arylaldehydes with allyltrichlorosilane using bisformamide organocatalysts 1 (Figure 1) which were prepared from cyclohexanediamine $[4,5]$. We thought that the catalysts $\mathbf{1}$ would also be useful for other reactions such as reduction of ketimines with trichlorosilane because trichlorosilane was activated by Lewis bases [6,7]. Since Matsumura et al. have reported the first chemo- and stereo-selective reduction of imines using trichlorosilane in the presence of formamides as Lewis bases [8], the reduction using various formamides has been reported. However, there are few reports on the reaction using bisformamides [9]. In addition, we thought that deprotection of the formyl groups of the catalysts 1 would give secondary diamine catalysts $\mathbf{2}$ which would also be utilized in further reactions such as aldol reactions [10]. The diamine catalysts 2 could also be converted to the bisformamide catalyst 1 by protection of amino groups, showing that both catalysts $\mathbf{1}$ and $\mathbf{2}$ were easily converted to each other. This recycle system of the catalysts has not been reported yet, thus our novel design

${ }^{*}$ Corresponding author.
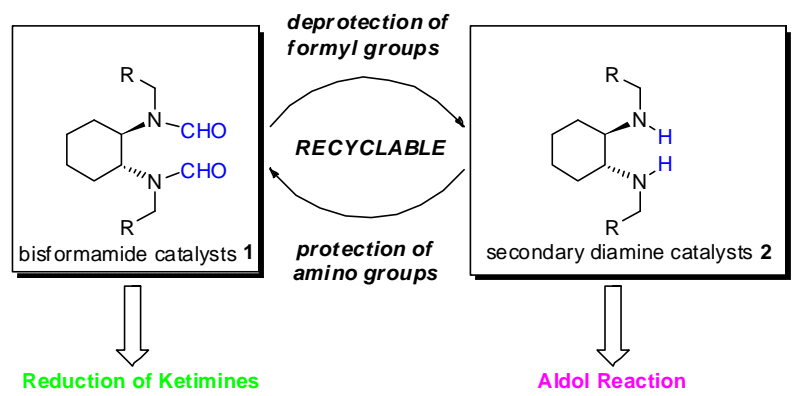

Figure 1. Novel design of recyclable catalysts.

concept would be useful for organic synthetic chemistry. Here we report the recyclable organocatalysts derived from cyclohexanediamine and application for reduction of ketimine and aldol reaction.

\section{Results and Discussion}

\subsection{Reduction of Ketimine with Trichlorosilane by Using Bisformamide Catalysts 1}

First, catalysts 1 were prepared from cyclohexanediamine as we reported before [4]. Reduction of ketimine 3 ( $2.5 \mathrm{mmol}$ ) with trichlorosilane (2 equiv to ketimine) was conducted in dichloromethane (2 mL) (Table 1). To our surprise, reaction proceeded under quite similar conditions as we reported before on the asymmetric allylation 
Table 1. Reduction of ketimine 3 in the presence of organocatalysts $1^{\mathrm{a}}$.

\begin{tabular}{ccccc}
\hline Entry & Catalyst $\mathbf{1}$ & Temp $\left[{ }^{\circ} \mathrm{C}\right]$ & Yield [\%] & ee [\%] \\
\hline 1 & 1a & r.t. & 97 & 15 \\
2 & $\mathbf{1 a}$ & 0 & 95 & 21 \\
3 & $\mathbf{1 a}$ & -20 & 92 & 21 \\
4 & $\mathbf{1 a}$ & -40 & 87 & 28 \\
5 & $\mathbf{1 a}$ & -78 & $81^{\mathrm{c}}$ & 39 \\
6 & $\mathbf{1 b}$ & -78 & 71 & 24 \\
\hline
\end{tabular}

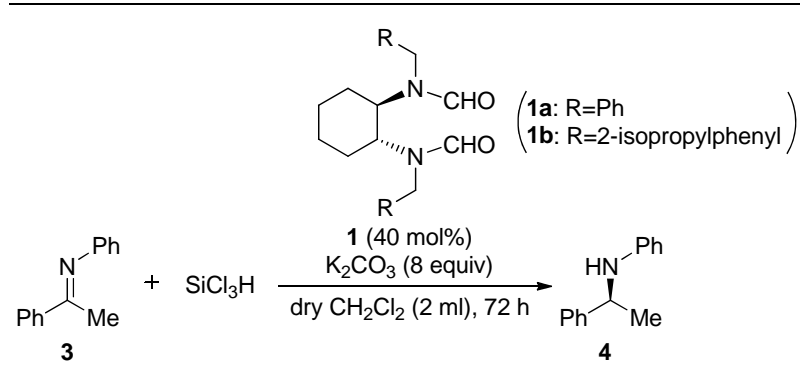

${ }^{\mathrm{a}}$ All reactions were carried out with ketimine $(2.5 \mathrm{mmol})$ and trichlorosilane (2 equiv to ketimine) in $\mathrm{CH}_{2} \mathrm{Cl}_{2}(2 \mathrm{~mL})$; ${ }^{\mathrm{b}}$ Isolated yield; ${ }^{\mathrm{c}}$ The absolute stereochemistry of major enantiomer was $S$.

reaction only except for temperature [5]. Reaction using the catalyst 1a afforded high yields of the corresponding amine 4 even at the low temperature (entries $1-5$ ). We also examined the enantiomeric excesses of 4 , and the best result was obtained at $-78^{\circ} \mathrm{C}(39 \%$ ee $(S)$ in entry 5$)$. Reaction with $\mathbf{1 b}$ also proceeded in high yield (entry 6$)$.

\subsection{Aldol Reaction of Acetone with 4-Nitrobenzaldehyde in the Presence of Diamine Catalysts 2}

Next, the catalysts 1 were converted to the corresponding diamine 2 using similar method as in the literature [11]. The aldol reaction of acetone with 4-nitrobenzaldehyde was carried out in the presence of $\mathbf{2}$ in various solvents (Table 2). Unfortunately, the use of the same solvent as in the Table 1 gave dehydrated product 6 (entry 1). However, water-containing solvents (entries $4-7$ and 9) or ionic liquid (entry 8) afforded the corresponding product 5. The reaction using $\mathbf{2 b}$ gave better yields (entries 5 - 9). High yield was observed in aqueous $\mathrm{NH}_{4} \mathrm{Cl}$ or brine (entries 7 and 9). The enantiomeric excess of the product was also examined and best ee was observed with $\mathbf{2 b}$ in brine at $0^{\circ} \mathrm{C}($ entry $9,29 \%$ ee $(R))$.

\section{Conclusion}

In conclusion, we have succeeded in reduction of ketimine with trichlrosilane in the presence of catalyst $1 \mathbf{a}$ in $81 \%$ $97 \%$ yields (up to $39 \%$ ee), and aldol reaction of 4 -ni-
Table 2. Aldol reaction of 4-nitrobenzaldehyde with acetone in the presence of organocatalysts $2^{a}$.

\begin{tabular}{ccccccc}
\hline Entry Catalyst & Solvent & \multicolumn{4}{c}{ Time (h) Temp $\left[{ }^{\circ} \mathrm{C}\right]$ Yield $[\%]^{\mathrm{c}}$ ee $[\%]^{\mathrm{d}}$} \\
\hline 1 & $\mathbf{2 a}$ & $\mathrm{CH}_{2} \mathrm{Cl}_{2}$ & 48 & r.t. & 0 & - \\
2 & $\mathbf{2 a}$ & $\mathrm{DMF}$ & 48 & r.t. & 0 & - \\
3 & $\mathbf{2 a}$ & $\mathrm{MeOH}$ & 48 & r.t. & trace & - \\
4 & $\mathbf{2 a}$ & $\mathrm{H}_{2} \mathrm{O}$ & 48 & r.t. & 45 & $3(S)$ \\
5 & $\mathbf{2 b}$ & $\mathrm{H}_{2} \mathrm{O}$ & 48 & r.t. & 47 & 14 \\
6 & $\mathbf{2 b}$ & brine & 48 & r.t. & 66 & 20 \\
7 & $\mathbf{2 b}$ & $\mathrm{NH}_{4} \mathrm{Cl}$ aq & 48 & r.t. & 82 & 14 \\
8 & 2b & {$[\mathrm{BMIM}] \mathrm{OTf}{ }^{\mathrm{b}}$} & 48 & r.t. & 79 & 5 \\
9 & $\mathbf{2 b}$ & brine & 72 & 0 & $81^{\mathrm{d}}$ & 29 \\
10 & 2b & brine & 72 & -20 & 0 & - \\
\hline
\end{tabular}

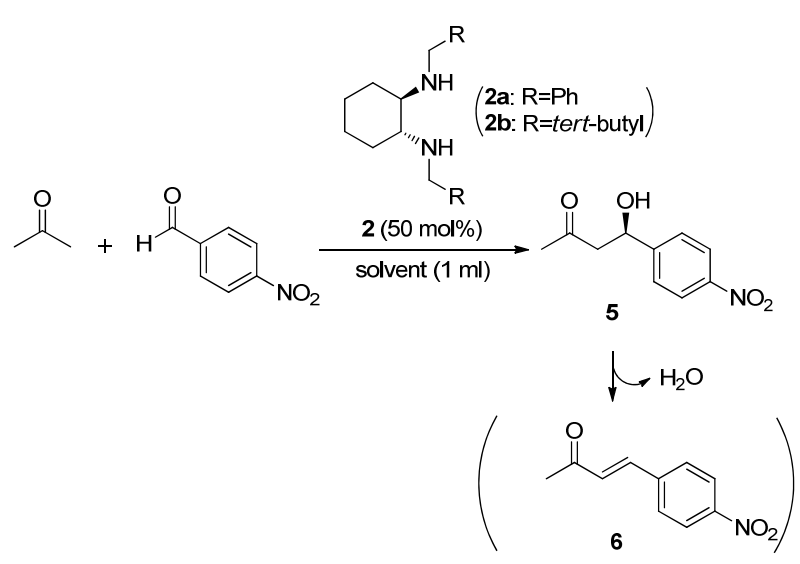

${ }^{\mathrm{a}}$ All reactions were carried out with acetone (10 equiv of aldehyde) and $p$-nitrobenzaldehyde $(1.0 \mathrm{mmol})$ in solvent $(1 \mathrm{~mL}){ }^{\mathrm{b}}[\mathrm{BMIM}] \mathrm{OTf}=1$ butyl-3-methylimidazolium trifluoromethanesulfonate; ${ }^{\mathrm{c}}$ Isolated yield; ${ }^{\mathrm{d}} \mathrm{The}$ absolute stereochemistry of major enantiomer was $R$.

trobenzaldehyde with acetone in the presence of catalyst 2b afforded the aldol adduct in $81 \%$ yield (29\% ee). Both catalysts $\mathbf{1}$ and $\mathbf{2}$ were easily converted to each other by changing the protecting groups.

\section{Experimental Section}

All organic substrates were commercially available and were used without any purification. Solvents for chromatography and extraction were purchased from commercial suppliers and used without further purification. Thinlayer chromatography (TLC) analysis of reaction mixtures was performed using Merck TLC plates (silica gel 60GF-254, $0.25 \mathrm{~mm}$ ) and visualized by using UV (254 $\mathrm{nm})$. The products were purified by flash column chromatography on silica gel 60 (Merck 1.09386.9025, 230 400 mesh). ${ }^{1} \mathrm{H}$ NMR spectrum was measured with JEOL JNM-AL300 BK1 (300 MHz) in $\mathrm{CDCl}_{3}$. 


\subsection{General Procedure for Reduction of Ketimine with Trichlorosilane by Using Bisformamide Catalysts 1}

To a stirred solution of catalyst $(1.0 \mathrm{mmol})$, pottasium carbonate ( 8.0 equiv to ketimine), ketimine $(2.5 \mathrm{mmol})$ in dry dichloromethane $(2 \mathrm{~mL})$ was added trichlorosilane $(2$ equiv to ketimine) at r.t. under Ar. The reaction was stirred for $72 \mathrm{~h}$, quenched with saturated aqueous $\mathrm{NaHCO}_{3}(1 \mathrm{~mL})$, and the mixture was filtered. The solvent was evaporated and the crude product was purified by column chromatography (dichloromethane:hexane $=$ 1:1) to give the corresponding product. The product was identified with the spectral data in the literature [12]. Enantiomeric excess was determined by HPLC with Chiralcel OD column (hexane:2-propanol $=9: 1$ ), flow rate $=1.0 \mathrm{~mL} / \mathrm{min}$, retention time: $8.2 \mathrm{~min}$ (major), 10.1 $\min$ (minor). ${ }^{1} \mathrm{H}$ NMR $\left(300 \mathrm{MHz}, \mathrm{CDCl}_{3}\right) \delta 7.34-7.26$ (m, 4H, Ph), $7.21-7.16(\mathrm{~m}, 1 \mathrm{H}, \mathrm{Ph}), 7.06$ (t, 2H, $J=7.9$ $\mathrm{Hz}, \mathrm{Ph}), 6.62$ (t, $1 \mathrm{H}, J=7.3 \mathrm{~Hz}, \mathrm{Ph}), 6.48$ (d, 2H, $J=7.7$ $\mathrm{Hz}, \mathrm{Ph}), 4.45$ (q, $1 \mathrm{H}, J=6.6 \mathrm{~Hz}, \mathrm{NHCH}), 3.97(\mathrm{~s}, 1 \mathrm{H}$, $\mathrm{NH}), 1.47\left(\mathrm{~d}, 1 \mathrm{H}, J=6.6 \mathrm{~Hz}, \mathrm{CH}_{3}\right)$.

\subsection{Aldol Reaction of Acetone with 4-Nitrobenzaldehyde in the Presence of Secondary Amine Catalysts 2}

To a stirred solution of catalyst $(0.5 \mathrm{mmol})$, 4-nitrobenzaldehyde $(1.0 \mathrm{mmol})$ in brine $(1 \mathrm{~mL})$ was added to the acetone (10.0 equiv to the aldehyde). The reaction mixture was stirred, and after the reaction was completed (monitored by TLC), dichloromethane was added to the mixture. The mixture was extracted with dichloromethane, and organic layers were dried over $\mathrm{Na}_{2} \mathrm{SO}_{4}$. After filteration, the solvent was evaporated to give the crude product which was purified by column chromatography (ethyl acetate:hexane $=2: 1$ ). The product was identified with the spectral data in the literature [13]. The enantiomeric excess was determined by HPLC with Chiralpak AS column (hexane/2-propanol $=95: 5$ ), flow rate $=1.0$ $\mathrm{mL} / \mathrm{min}$, retention time: $10.6 \mathrm{~min}$ (mionr), $13.6 \mathrm{~min}$ (major). ${ }^{1} \mathrm{H}$ NMR $\left(300 \mathrm{MHz}, \mathrm{CDCl}_{3}\right) \delta 8.20(\mathrm{~d}, 2 \mathrm{H}, J=$ $8.8 \mathrm{~Hz}, \mathrm{Ph}), 7.54(\mathrm{~d}, 2 \mathrm{H}, J=8.8 \mathrm{~Hz}, \mathrm{Ph}), 5.25-5.29(\mathrm{~m}$, $1 \mathrm{H}, \mathrm{CHOH}), 3.67$ (brs, $1 \mathrm{H}, \mathrm{OH}), 2.85-2.87\left(\mathrm{~m}, 2 \mathrm{H}, \mathrm{CH}_{2}\right)$, $2.23\left(\mathrm{~s}, 3 \mathrm{H}, \mathrm{CH}_{3}\right)$.

\section{REFERENCES}

[1] A. Berkessel and H. Gröger, Eds., "Asymmetric Organocatalysis: From Biomimetic Concepts to Applications in Asymmetric Synthesis," Wiley-VCH, Weinheim, 2005. http://dx.doi.org/10.1002/3527604677

[2] P. I. Dalko, Ed., "Enantioselective Organocatalysis: Reactions and Experimental Procedures," Wiley-VCH, Wein- heim, 2007.

[3] B. List, Ed., "Asymmetric Organocatalysis," Springer, Berlin, 2009.

http://dx.doi.org/10.1007/978-3-642-02815-1

[4] K. Ishimaru, K. Ono, Y. Tanimura and T. Kojima, "Novel chiral Bisformamide-Promoted Asymmetric Allylation of Benzaldehyde with Allyltrichlorosilane," Synthetic Communications, Vol. 41, No. 24, 2011, pp. 3627-3634. http://dx.doi.org/10.1080/00397911.2010.519841

[5] Y. Tanimura and K. Ishimaru, "Asymmetric Allylation Reactions of Aromatic Aldehydes with Allyltrichlorosilane Catalyzed by Chiral Bisformamide-Type Organocatalysts," Tetrahedron: Asymmetry, Vol. 23, No. 5, 2012, pp. 345-349.

http://dx.doi.org/10.1016/j.tetasy.2012.02.015

[6] R. A. Benkeser and D. C. Snyder, "Trichlorosilane-Imine Complexes. A New Method for the Reduction of Imines to Amines," Journal of Organometallic Chemistry, Vol. 225, No. 1, 1982, pp. 107-115.

http://dx.doi.org/10.1016/S0022-328X(00)86814-X

[7] S. Kobayashi, M. Yasuda and I. Hachiya, "Trichlorosilane-Dimethylformamide $\left(\mathrm{Cl}_{3} \mathrm{SiH}-\mathrm{DMF}\right)$ as an Efficient Reducing Agent. Reduction of Aldehydes and Imines and Reductive Amidation of Aldehydes under Mild Conditions Using Hypervalent Hydridosilicates," Chemistry Letters, No. 5, 1996, pp. 407-408.

http://dx.doi.org/10.1246/cl.1996.407

[8] F. Iwasaki, O. Onomura, K. Mishima, T. Maki and Y. Matsumura, "Catalytic Activation of Trichlorosilane for Efficient and Stereoselective Reduction of Ketones," Tetrahedron Letters, Vol. 40, No. 42, 1999, pp. 7507-7511. http://dx.doi.org/10.1016/S0040-4039(99)01554-3

[9] C. Baudequin, D. Chaturvedi and S. B. Tsogoeva, "Organocatalysis with Chiral Formamides: Asymmetric Allylation and Reduction of Imines," European Journal of Organic Chemistry, No. 16, 2007, pp. 2623-2629. http://dx.doi.org/10.1002/ejoc.200700058

[10] R. Mahrwald, Ed., "Modern Aldol Reactions," WileyVCH, Weinheim, 2004. http://dx.doi.org/10.1002/9783527619566

[11] J. C. Sheehan and D.-D. H. Yang, "The Use of $N$-Formylamino Acids in Peptide Synthesis," Journal of the American Chemical Society, Vol. 80, No. 5, 1958, pp. 1154-1158. http://dx.doi.org/10.1021/ja01538a036

[12] T. Kanemitsu, A. Umehara, R. Haneji, K. Nagata and T. Itoh, "A Simple Proline-Based Organocatalyst for the Enantioselective Reduction of Imines Using Trichlorosilane as a Reductant," Tetrahedron, Vol. 68, No. 20, 2012, pp. 3893-3898. http://dx.doi.org/10.1016/j.tet.2012.03.035

[13] Z. Tang, Z.-H. Yang, X.-H. Chen, L.-F. Cun, A.-Q. Mi, Y.-Z. Jiang and L.-Z. Gong, "A Highly Efficient Or- ganocatalyst for Direct Aldol Reactions of Ketones with Aldehydes," Journal of the American Chemical Society, Vol. 127, No. 25, pp. 9285-9289.

http://dx.doi.org/10.1021/ja0510156 